\title{
Exposición fetal a alcohol
}

\author{
SOFÍA AROS A. ${ }^{1}$ \\ 1. Unidad de Agudos, Servicio de Pediatría, Complejo de Salud San Borja Arriarán. \\ Instituto de Investigación Materno Infantil, IDIMI, Campus Centro, Facultad de Medicina, Universidad de Chile. \\ Extraído de Sexta Edición del libro "Guías de Práctica Clínica en Pediatría 2008" del Servicio de Pediatría del Complejo \\ Hospitalario San Borja Arriarán. Autorizado por su Editor Dr. Francisco Barrera Q.
}

Palabras clave: Alcohol, alcoholismo fetal, teratogénico. Síndrome de alcohol fetal, SAF.

\section{Introducción y Magnitud del problema}

El alcohol es un teratógeno. Aunque no reconocido hasta 1968, hoy es identificado como la principal causa ambiental de retardo mental. Es completamente prevenible, pero una vez establecido, el daño neurológico es permanente. El consumo de bebidas alcohólicas en el embarazo es un importante problema de salud pública, especialmente en Chile, uno de los siete países en el mundo con mayor prevalencia de abuso de alcohol. Los niños expuestos están en alto riesgo de dificultades escolares, problemas legales, abuso de sustancias y problemas de salud mental.

Se ha informado que entre el $20 \%$ y el $65 \%$ de las mujeres lo ingieren en algún momento durante la gestación y que el $5 \%$ a $10 \%$ lo hacen en niveles suficientes como para poner al feto en riesgo. Muchos trabajos demuestran que la ingesta promedio de un trago al día (12 gramos de alcohol absoluto equivalente a 100 cc de vino, $300 \mathrm{cc}$ de cerveza, $30 \mathrm{cc}$ de pisco, 25 cc de whisky), pone al niño en riesgo de presentar al nacimiento retardo del crecimiento y defectos relacionados con el alcohol. Tanto la ingesta diaria como el beber episódico son de riesgo para el feto. Con cantidades consideradas de muy alto riesgo como 4 tragos al día, el $30 \%$ a $50 \%$ de los niños expuestos presenta daño atribuible a alcohol. Se ha demostrado que el beber episódico (binge) definido como 5 o más tragos por vez, reportado en alrededor de $13 \%$ de las embarazadas, es más dañino para el sistema nervioso. En los últimos años la educación aplicada a la población general ha logrado disminuir el consumo ocasional en mujeres embarazadas, pero no el consumo de riesgo. En Chile, un estudio prospectivo realizado en el Consultorio de Maipú en Santiago, demuestra que un $57,4 \%$ de las mujeres bebe alcohol en algún momento del embarazo, un 3,7\% reconoce ingesta en los niveles descritos como de riesgo fetal ( 1 trago al día) y al menos un $1,1 \%$ de ellas reconoce beber cantidades que constituyen muy alto riesgo. La identificación de las mujeres que están consumiendo alcohol y drogas se hace especialmente difícil porque la mayoría tiende a ocultar este antecedente. $\mathrm{La}$ mujer habitualmente niega o minimiza el consumo en una primera entrevista, especialmente si se efectúa la pregunta directamente. Si es posible generar un ambiente previo de cierta confianza con un entrevistador amistoso se logra una mayor y mejor información, que facilitará la intervención. Es de ayuda utilizar elementos indirectos que sugieren el beber excesivo; en el estudio en Chile se identifica como indicadores

Correspondencia a:

Sofía Aros A.

E-mail: saros@med.uchile.cl 
útiles de consumo excesivo de alcohol el haber comenzado a beber a temprana edad, el sufrir episodios de embriaguez, la baja autoestima, los problemas para alimentarse y relacionarse con otras personas y los trastornos del sueño.

Así como es difícil que la madre reporte la ingesta, también es difícil identificar precozmente al niño expuesto. Se ha estimado que la incidencia de Síndrome Alcohol Fetal (SAF) es de 0,3 a 3,0 por 1000 recién nacidos vivos (RNV), pero el número de niños expuestos con efectos menos severos puede ser mucho mayor (hasta 1 en $300 \mathrm{RNV})$. Además de producir el SAF, que es el extremo más severo del espectro, el beber durante el embarazo puede resultar en una amplia gama de alteraciones que hasta hace poco se agrupaban bajo el nombre de Efectos de Alcohol Fetal y que hoy se prefiere denominar Espectro de Desórdenes Alcohol Fetal.

\section{Patogenia}

Ha sido muy difícil comprender los mecanismos teratogénicos del alcohol, sobretodo porque es muy improbable que solo uno de ellos sea el responsable de los variados efectos observados en el desarrollo embrionario y fetal, como consecuencia de la ingesta de este tóxico. Sabemos que el efecto depende en forma muy importante del momento del desarrollo en que se produce la exposición, ya que hay períodos críticos de vulnerabilidad y se ha descrito daño por alcohol aún en la etapa de preimplantación, incluyendo la exposición de las células paternas. Pero también influye la forma de beber de la embarazada, la dosis, la duración del consumo y la susceptibilidad individual de la madre y del niño, dada probablemente por factores genéticos y nutricionales, aún no claramente identificados.

A iguales cantidades de alcohol consumidas por la mujer gestante algunas células fetales mueren, otras disminuyen su proliferación y otras parecen no afectarse. Determinar la vulnerabilidad selectiva de cada célula es clave para comprender la patogenia. Los mecanismos ya identificados incluyen muerte celular, reducción de la proliferación, alteraciones de migración, pérdida de adhesión, alteraciones en la diferenciación y función celular y disregulación de genes. Además la ingesta de alcohol materna genera radicales libres produciendo mayor daño celular: daño mitocondrial por aumento del calcio intracelular, déficit de zinc que produce muerte selectiva de células de la cresta neural, estimulación del metabolismo de la enzima CYPZE1 del complejo citocromo P450 y constricción de arterias umbilicales en cada episodio de ingesta alcohólica con mecanismo de isquemia/reperfusión. También se ha demostrado que el alcohol afecta receptores de membranas de neurotransmisores y disminuye el crecimiento de dendritas; inhibe en forma competitiva la enzima que transforma retinol a ácido retinoico, metabolito que modula los genes que regulan el desarrollo y produce déficit de folato, también fundamental en las etapas iniciales del período embrionario. Comprender los complejos mecanismos patogénicos del alcohol en el embarazo, es fundamental para lograr intervenciones exitosas.

Con Resonancia nuclear magnética se ha encontrado alteraciones en regiones seleccionadas del vermis cerebeloso, cuerpo calloso y ganglios basales de niños expuestos a alcohol. Se ha sugerido también que las alteraciones cerebrales y la dismorfia facial en SAF son consistentes con una forma leve de holoprosencefalia.

Por otra parte, es muy difícil establecer las cantidades que constituyen riesgo, porque depende de múltiples factores y se ha descrito efectos con ingestas mínimas. El crecimiento intrauterino se afecta más por el consumo continuo; si la exposición es en el primer trimestre del embarazo se produce retardo del crecimiento intrauterino simétrico (peso, talla y circunferencia craneana afectados), si es en el segundo o tercer trimestre compromete más el peso y tiene más posibilidades de recuperación. El sistema nervioso central se puede ver afectado con cualquier forma de consumo materno, pero se deteriora más con la ingesta de grandes cantidades ocasionales; las células nerviosas no tienen capacidad de recuperación, y las alteraciones estructurales y/o funcionales varían de acuerdo al momento de exposición. Los efectos morfológicos en otros sistemas (espe- 
cialmente cardíaco, urogenital y musculoesquelético) también son permanentes y dependen del momento de gestación en que son afectados por el alcohol.

La raza, edad, ocupación y clase social influyen en el hábito de beber de las mujeres. Es más probable que las bebedoras también consuman tabaco y drogas y que sufran otros problemas ambientales durante su embarazo. Más allá del embarazo, las mujeres que beben en forma excesiva y/o son alcohólicas, son menos capaces de proporcionar un ambiente óptimo a su hijo. El apoyo social, el nivel de stress y la estructura familiar también afectan el progreso de este niño, ya vulnerable por su exposición prenatal.

\section{Prevención}

Lo óptimo sería eliminar el alcohol durante el embarazo. No se ha establecido una dosis segura. La Academia Americana de Pediatría recomienda la abstención del consumo de alcohol en mujeres embarazadas o que estén planificando un embarazo. Más aún, la recomendación debiera incluir a todas las mujeres con posibilidad de embarazarse. Es necesario motivar a las gestantes a abstenerse aún de ingestas mínimas, ya que aunque los efectos del beber leve y moderado pueden ser menores, estos niños quedan más vulnerables ante un ambiente que puede ser pobre y afectarlos más que a otros niños.

\section{Diagnóstico}

El SAF se define como un defecto congénito permanente causado por el consumo de alcohol durante el embarazo. Clásicamente los elementos claves a considerar son alteración del crecimiento, dismorfia facial y alteración neurológica, pero hasta ahora no hay una definición clínica estandarizada de SAF y para el pediatra el diagnóstico puede ser muy difícil.

Hay distintas pautas de diagnóstico desarrolladas para el niño que ha estado expuesto a alcohol in útero, pero coinciden en la mayoría de los criterios. Se considera signos de anormalidad en cada una de las tres siguientes categorías:

\section{Retraso de crecimiento}

Confirmación de peso y/o talla $\leq$ percentil 10 en cualquier momento de evolución prenatal y/o postnatal, con tablas adecuadas para raza, edad gestacional, sexo y edad

\section{Dismorfia facial}

Fisuras palpebrales pequeñas $(<\mathrm{p} 10)$, filtrum largo y aplanado (score 4 ó 5 en guía labio/ filtrum de la Universidad de Washington) y labio superior fino (score 4 ó 5).

\section{Alteraciones sistema nervioso central}

- Estructurales: perímetro craneano $\leq \mathrm{p} 10$. Anormalidades estructurales cerebrales (neuroimagen) clínicamente significativa: microcefalia, agenesia parcial o total del cuerpo calloso, hipoplasia cerebral.

- Alteraciones neurológicas: signo neurológico fuera de límites normales no atribuible a injuria postnatal.

- Funcionales: retraso de desarrollo psicomotor o déficit cognitivo global (test de Coeficiente Intelectual $<2 \mathrm{DS})$ o déficit funcional $(<1$ DS) en al menos 3 de las siguientes áreas: cognitiva, motora, de ejecución, atención o grado de actividad, lenguaje, memoria, habilidades sociales, sensoriales.

Si se evidencia alteración en las 3 áreas se puede diagnosticar Síndrome Alcohol Fetal. Siempre es necesario consignar si está confirmada la exposición materna a alcohol, pero si están presentes los 3 elementos clínicos, no es indispensable para el diagnóstico.

La dismorfia facial es la alteración más específica, pero debe ser evaluada idealmente por un experto en genética. Existe un programa computacional validado que analiza la facies en una foto del niño y que en base a las fisuras palpebrales y el filtrum otorga un puntaje que se correlaciona muy bien con el diagnóstico global. Por otra parte, el fenotipo varía con la edad. Las características faciales son menos evidentes al nacimiento, muy notorias en la lactancia e infancia y luego disminuyen y aún desaparecen en la adolescencia y edad adulta.

En la disfunción neurológica no siempre hay microcefalia, el retraso cognitivo no necesaria- 
mente cae en el rango de deficiencia mental y los problemas de atención no siempre constituyen el clásico síndrome de déficit atencional. Además parecen afectarse áreas específicas que se traducen en alteraciones del aprendizaje especialmente de la lectura, el lenguaje y las habilidades matemáticas, falta de capacidad de abstracción, falla en la razón y el juicio que comprometen la capacidad de aprender de una experiencia. Estas últimas alteraciones no son fácilmente diagnosticadas y pueden afectar significativamente la inserción social, la vida afectiva, estudiantil y posteriormente laboral de estos pacientes.

La mayoría de los niños expuestos no presentan todas las características necesarias para el diagnóstico de SAF, pero sus alteraciones en el neurodesarrollo pueden ser las mismas y está claramente establecido que estos niños no son diagnosticados ni apoyados oportunamente. Por esto se recomienda evaluar en forma dirigida y periódica cuando existen las siguientes condiciones:

- antecedente de exposición in útero a cantidades de alcohol de riesgo para el feto (más de 1 trago al día en promedio o episodios con ingesta de 3 o más tragos)

- presencia de las 3 alteraciones faciales sin otros hallazgos

- presencia de 1 o más características faciales con alteración de peso y/o talla

- una o más características faciales con 10 más alteraciones de SNC

- presencia de 1 o más características faciales con alguna alteración de crecimiento y 1 o más alteraciones de SNC.

En este grupo de niños se puede hacer el diagnóstico de SAF parcial, Defectos de Nacimiento Relacionados a Alcohol o Defectos del Neurodesarrollo Relacionados a Alcohol, pero lo realmente importante es brindarles una posibilidad de diagnóstico, apoyo terapéutico y seguimiento.

Entre las otras alteraciones congénitas descritas en asociación con consumo materno de alcohol en la gestación se incluye:

- Cardíacas: comunicación interauricular, comunicación interventricular, tetralogía de Fallot.
- Esqueléticas: clinodactilia, uñas hipoplásicas, camptodactilia, hemivértebras, escoliosis, pectum excavatum y carinatum, contracturas de flexión.

- Renales: hipoplasia renal, displasia renal, riñón en herradura, duplicación ureteral, hidronefrosis.

- Oculares: estrabismo, alteraciones de refracción por globos oculares pequeños, anomalías vasculares de retina.

- Auditivas: sordera de conducción, sordera sensorioneural.

- Otras: virtualmente todas las malformaciones han sido descritas en algún paciente con SAF. La especificidad del efecto teratogénico del alcohol en la mayoría de estas anomalías permanece incierta.

\section{Diagnóstico diferencial}

Debe estar en manos del genetista e incluye:

- Síndrome de Aarskog: talla baja, retraso mental, filtrum ancho, hipertelorismo y rodete peneano.

- Síndrome de Williams: retraso del crecimiento, coeficiente intelectual bajo, fisuras palpebrales cortas, filtrum largo, escleras azules, cardiopatía, hiperlocuacidad.

- Síndrome de Noonan: baja estatura, retraso mental, orejas de implantación baja, retrognatia, cúbito valgo, criptorquidia, cardiopatía.

- Síndrome de Dubowitz: retraso del crecimiento, microcefalia, retraso del desarrollo psicomotor, hiperactividad, eczema, fisuras palpebrales pequeñas con ptosis y blefarofimosis, orejas prominentes.

- Síndrome de hidantoína fetal: déficit de crecimiento, leve retraso mental, fisura palatina, hipertelorismo, uñas hipoplásicas, estrabismo, nariz pequeña.

- Efectos fetales de fenilquetonuria materna: retardo mental, hipertelorismo, retraso del crecimiento pre y postnatal, microcefalia, fisuras palpebrales pequeñas, filtrum largo y aplanado con labio superior delgado, antecedente de patología materna. La facies de este niño es tan similar al SAF que se ha planteado algún metabolito común. 


\section{Manejo}

En los niños expuestos a alcohol durante el embarazo, las intervenciones específicas posibles no han sido aún claramente establecidas. El compromiso neurológico es el área donde debiera realizarse el mayor esfuerzo en detección precoz, apoyo y rehabilitación para hacer menos severas las discapacidades. El diagnóstico permite disminuir la ansiedad de los padres ante alteraciones y pocos progresos y los ayuda a adecuar, idealmente junto a los profesores, las exigencias, evitando castigos y frustraciones. Si es posible, mejorar el ambiente que rodea a este niño, se puede atenuar el riesgo de desarrollar conductas de riesgo social.

Es fundamental incluir:

- Sospecha.

- Evaluación multidisciplinaria.

- Apoyo nutricional.

- Intervención neurológica y psicológica.

- Servicio Social.

- Programas de intervención escolar individual para aprovechar al máximo el potencial

- Educación a la madre para futuros embarazos.

Se ha descrito algunos factores protectores:

- Diagnóstico precoz (ojalá antes de 6 años).

- Educación especial individualizada.

- Terapia especializada.

- Entrenamiento a padres (cuidadores) en manejo conductual y de situaciones especiales.
- Ambiente protector, amoroso y estable.

- Necesidades básicas cubiertas.

- Ausencia de violencia.

\section{Referencias}

1.- Fetal Alcohol Syndrome: Guidelines for Referral and Diagnosis. NCBDDD, CDC and NTFFAS/FAE. July 2004.

2.- Manning MA, Hoyme HE. Fetal alcohol spectrum disorders: A practical clinical approach to diagnosis. Neurosc Biobehav Rev 2007; 31: 230.

3.- Aros S, Mills JL, Torres C, Henríquez C, Fuentes A, Capurro $T$, et al: Prospective Identification of Pregnant Women Drinking Four or More Standard Drinks ( $\geq 48 \mathrm{~g}$ ) of Alcohol Per Day. Subst Use Misuse 2006; 41: 183-97.

4.- Spohr HL, Willms J, Steinhausen HC: Fetal alcohol spectrum disorders in young adulthood. J Pediatr 2007; 150: $175-9$.

5.- Signore C, Aros S, Morrow J, Troendle J, Conley M, Flanigan E, et al: Markers of Oxidative Stress and Systemic Vasoconstriction in Pregnant Women Drinking $>/=48 \mathrm{~g}$ of Alcohol per Day. Alcohol Clin Exp Res 2008; 32: 1893-8.

6.- Flanigan E, Aros S, Bueno M, Conley M, Troendle J, Cassorla $F$, et al: Eye malformations in children with heavy alcohol exposure in utero. J Pediatr 2008; 153: 391-5.

7.- Avaria M de L, Mills J, Kleinsteuber K, Aros S, Conley $M$, Cox $C$, et al:. Peripheral nerve conduction abnormalities in children exposed to alcohol in utero. J Pediatr 2004; 144: 338-43. 